this in mind, and again returning to the acute inflammatory onset of the disease, with pain followed by paralysis, and with the presence of incipient disease at the apices of both lungs, I do not see how we could well escape the diagnosis that the third nerve had become compressed from lymph locally effused about its trunk, the result of tubercular inflammation. It was this diagnosis upon which the treatment of the case was founded.

If anything conld be done in such a case it must be done quickly, and where easily destroyed and vital parts are attacked by inflammation and are beyond the reach of local treatment tbere is only one drug which is worth serions consideration, and that drug is mercury, iodide of potassium coming a long way afterwards. Accordinuly we gave this boy ten minims of solution of perchloride of mercury with one grain and a half of iodide of potaesium every three hours, not hopefully I must confess, for the prognosis looked most un promising. The pain continued next day, the temperature ranging $102 \cdot 2^{\circ}, 98^{\circ} 6^{\circ}$, and $99^{\circ} 6^{\circ}$. On the 15 th the temperature was $1002^{\circ}, 1022^{\circ}, 994^{\circ}, 996^{\circ}$. $16 \mathrm{th}: 102^{\circ}, 101^{\circ}$; pulse 120 ; tongue red and glazed; pain still marked; evening temperature $102^{\circ}$. 17 th : $6 \mathrm{~A} . \mathrm{M} ., 101^{\circ}$; 10 A.M , $994^{\circ}$. Bowels not open; tongue red still; dull constant pain in right temporal region, parts about right orbit appreciably horter to the hand than on the opposite side. Movement of eye much improved; can half opeu eye; inward rotation almost complete; pupils a shade larger ; pupils act to light. Chest signs improved : spleen still perceptible. Eveuing temperature $100^{\circ}$. The perchloride of mercury to be increased to fifteen minims, and the iodide of potassium to two grains, every three hours.-18th: Temperature $99.8^{\circ}$; pain better; bowels confined. Ophthalmoscopic examination discovered nothing abnormal. Evening temperature $99^{\circ}$. The symptoms now rapidly amended. On the 2 lst the pain had gone, the temperature was subnormal, and there was no return of pyrexia, and the boy has now (February 3rd) been up two days, all paralysis has vanished, the chest signs, too, have almost completely cleared up, there being now only slight harshness of breath sound at the right apex.

The last question we have to ask is, Does the complete subsidence of symptoms and signs under treatment by mercury and iodide warrant the conclusion that the disease was not tubercular after all? I think not. Any considerable post-mortem experience will suffice to assure us that miliary tubercle per se is not a very serious product. If universally and thickly distributed, it is, of course, a part of a general and severe blood contamination, and, further, by mere aggregate bulk, impedes and arrests vital functions; otherwise, when locally distributed, the symptoms occasioned are mainly proportional to the inflammatory lesions started by the tubercle. Apart from such inflammatory association, tubercle may, and frequently does, shrivel, or become horny and quiescent. I would by no means advocate the treatment of tubercular lesions generally by mercury; but when the pia mater or peritoneum is acutely involved and in the first stage of the disease, I believe mercury to be worthy of trial. Some of you may remember a countryman in No. 9 bed of this ward, who was admitted with peritonitis. There was no history of syphilis, and the man did not look phthisical; but he had some chronic disease at the apex of the left lung. We plied him with small doses of mercury guarded with opium, and kept the gums tender for some weeks, during all which time he improved; and he left the hospital convalescent. In any case, where we can find evidence of any special poison or diathesis, as that of syphilis or rheumatism, we of course boldly adopt the indication and give mercury and iodide freely in the one case, or salicylate of soda in the other, and of ten with brilliant results. I wish, however, to urge you in the far more serious cases which are presumably tubereular, not on that account, to stand hand-folded and in despair, or content only to apply a little ice to the head, and to give a little bromide. If you catch the case in a sufficiently early stage try mercurial treatment. Remember the frequency with which you meet with a local tuberculosis in the lungs with often transient activity of symptoms; any similar attack affecting the meninges of the brain is attended with far graver symptoms, and commonly proves fatal, but we must not regard it as necessarily beyond the reach of treatment. If the view I have taken of this case be correct, the tendency to a recurrence of the malady must not be forgotten, although the boy appears now to be thoroughly convalescent.
ON

\section{DIGITAL EXPLORATION OF THE BLADDEP THROUGH INCISION OF THE URETHRA FROM THE PERINEUM.}

BY SIR HENRY THOMPSON, F.R.C.S.,

SURGEON-EXTRAORDINARY TO H.M. THE KING OF THE BELGIANS, CON SULTING SURGEON TO UNIVERSITY COLLEGE, ETC.

THE subject of digital exploration of the bladder has excited much interest in the profession, if $I$ may judge from the discussion which took place respecting it last month at the Royal Medical and Chirurgical Society, and from the numerous inquiries $I$ have lately received in relation to it. It is in reply to these, rather than as an attempt to treat the subject fully, that I desire to offer a few remarks respecting it. For myself the proceeding has for some long time been regarded as a promising means of prosecuting dia. gnosis in exceptional cases, and still further as likely to constitute an efficient mode of treatment for some of them. Accustomed to use the index-finger as much as possible in a large exprience of lithotomy in its several forms-lateral, median, bilateral, and medio-bilateral, -I have been in the habit of examining the neck of the bladder, and scrutinising, with much iuterest, its characters, often greatly differing as they do in the cases of elderly men. But it is only during the last few years that I have gradually realised the fact that it is possible, in not a few cases, to explore throngh a small perineal incision the whole, or nearly the whole, of the internal surface of the bladder with the index finger. A necessary condition, of course, is that the bladde should be empty ; and in that condition it is-as is sumetimes perhaps not sufficiently recognised-no longer a cavity; as represented in diagrams, but a mere cul-de-sac at the end of the urethra. Taking it for granted that the incisions to be made, which involve only the urethra with the tissues between it and the surface, and not at all the bladder and prostate, enable the operator to place the last joint of his left index finger within the neck and thus to draw it some what towards him, the exploration may be accomplished in the following manner. Maintaining his finger at the spot described, the operator should stand up at the foot of the table, a little to the left of the patient (who is in the litho tomy position), so as to make firm pressure with the right hand above the pubes, the resistance of the abdominal muscles being overcome by the influence of ether. He may now easily feel, unless the patient be very stout, the opposite side of the bladder coming into contact with the tip of his finger; and by concerted movements of supra-pubic pressure by the right hand, with slight movements of the left index in the bladder, almost every portion of the internal coat of the latter may be brought under examination. If the patient be thin, the proceeding is easy; it becomes less so in pro portion to the depth of perineum and thickness of the supra pubic coverings, both of which are increased by fat. In the latter case aid may be rendered by an assistant, who makes firm pressure with both his hands, but the operator should also employ, if he can, the concerted movements described.

Now, I think, it will be admitted that, however effective is the ordinary examination of the bladder by the sound and by rectal examination, and it amply suffices for the great majority of cases, there are still a few obscure examples 0 disease, respecting which, even in the most experienced hands, examination does not reveal facts which it is of the utmost importance to ascertain. This being so, the question arises, Can digital exploration of the bladder be performed without much risk to the patient? I unhesitatingly answer in the affirmative. The results of external urethrotomy, on a grooved staff previously introduced, an operation largely performed by Professor Syme about thirty years ago-result which were jealously watched and closely scrutinised-go far to warrant this reply. But although the external inci sions in his proceeding were almost identical in situation with those I shall advise for digital exploration, the internal incision in Syme's operation was made not only in tissue very often largely diseased, but was far more extensive than that required for the purpose now in view. To this evidence I may add that I have myself opened the urethra from the perineum many times for various purposes besides that of extracting calculus; and I do not recollect a single 
fatal result. Fifteen cases of external division of stricture on a staff are included among them. Next, the method of operating in order to reach the bladder from the perineum demands a few words. I think there is little ground for doubting that a vertical median incision-that is, in the line of the raphe-introduces the finger by the shortest and most directronte. The prominence formed by the operator's bended knuckles, while using his index-finger as an explorer, lies equidistant between the nates, and is firmly pressed on the perineum in a straight line from the external surface towards the centre of the bladder. Any line right or left of the median must of necessity lead obliquely to the centre, and be a longer line, because it commences at a point on the external surface more distant from the neck of the bladder than is the raphe of the perineum. Accordingly I always adopt the central incision, using a median grooved staff, and a long, straight, narrow-bladed knife, with the back blunt to the point. Having placed the lef index-finger in the rectum the knife may be introduced, edge upwards, about three-quarters of an inch above the anus, with or without a small preliminary incision of the skin (I prefer the former), until the point reaches the staff about the apex of the prostate gland, where it divides the urethra for half an inch or so, and is then drawn out, cutting upwards a little in the act, but so as to avoid any material division of the bulb. The left index-finger is now removed from the rectum, and following by the groove of the staff, slowly passes through the neck of the bladder as the staff is withdrawn, when exploration is made, as described above. A moderate division of the bulb when made in the middle line is not to be feared as a cause of hæmorrhage, while an incision involving the side of the bulb, and nearer to the entry of its artery, is more prone to bleed freely. Hence some have preferred another mode of incision in order to avoid it-namely, one of crescentic form, with the convexity upwards, just above the anus; the dissection to be carried transversely to the apex of the prostate, and opening the urethra there, as before mentioned.

Since the case of exploration which I performed in November, 1880, where I discovered and removed the tumour presented (together with the patient) at the Royal Medical and Chirurgical Society on the 11th of April last, I have made digital exploration of the bladder, in the manner above described, in four other cases. I append a brief note of each here, by way of showing its nature and the results, and I venture to think that they will be regarded as fully warranting a resort to the operation, and that the effect in three instances was a manifest gain to the patient.

CASE 1.-A gentleman, aged forty-two ; micturition frequent ; florid blood passed almost daily for nearly two years ; occasional attacks of cystitis with phosphatic deposits. On June 27th, 1881, Mr. Clover gave ether. Having performed the operation described, I could detect neither calculous matter nor any structural change. A tube was tied in for five days, by which all the urine passed, and it was now free from bloody mucus. The tube was removed, and the wound soon healed. He was greatly improved, and is now living a very active life. He occasionally passes blood, and has some frequency of micturition, but is better than for years before.

CASE 2.-A gentleman, aged fifty-four. I cut him for rather a large uric-acid stone in 1880 ; he made a fair recovery, but had cystitis afterwards, pasing phosphatic con. cretions, and often blood; a condition resembling that which sometimes follows lithotrity. On June 16th, 1881, Mr. Clover gave ether. I explored for impacted calculu», \&c., bat could detect no deviation whatever from the normal condition. The tube was tied in four days, after which the wound rapidly healed, and no improvement could be noted. He is still under observation, and on the whole slowly improving.

CASE 3. - A rentleman, aged sixty-eight. Has passed all urine for several months by catheter, and for the greater part of the time much blood and mucus have been mixed with it. He has also been diabetic for a considerable period. Before operating I had the advantage of Sir William Jenner's opinion about the case.-Feb. 10th, 1882: In exploring I found only a small flake of phosphatic matter, apparently adhering to the surface of the bladder, and nothing else $a b$ normal. The tube was tied in eight days, after which the wound healed rapidly. He never had a trace of blood from this time, and the urine has been almost free from mucus he requires the catheter precisely as before. On April 15th he returned to the country very ill and feeble with diabetes.
CASE 4.-A gentleman, aged sixty. I formerly crushed a phosphatic calculus; he had long passed all urine by ca theter with great pain and frequency, with much cystitis and recurring phosphatic deposits. His suffering was so severe that he begged the bladder might be opened. - March 20th, 1882: I made the exploration in presence of Dr. Chepmell, Dr. Barton Smith, and Mr. Hayward, and could not detect any abnormal condition. The tube was tied in for seven days, after which the wound rapidly healed. The patient uses the catheter now only about every three or four hours, the character of the urine is much improved; he is actively occupied, the relief to suffering being very considerable, and he is himself more than satisfied with the result of the operation. Wimpole-street, $\mathbf{W}$.

\section{SNAKE POISON, TREATED SUCCESSFULLY WITH LIQUOR POTASSE,}

\section{WITH REMARKS.}

By Retired Deputy Surg. -Gen. JOHN SHORTT, M.D, M.R.C.P.L., F.L.S., \&c. \&c., Madras Army.

THE two following cases of snake-bite are of special interest just now, more particularly as Dr. J. B. 'de Lacerda, of Rio Janeiro, states that he has found the permanganate of potash to destroy snake poison completely. Allow me to state there is nothing new in this. I long ago, in 1869 and '70, stated that an antidote was to be found in the liquor potassæ; this fact I publicly demonstrated in the most satisfactory manner to all the medical officers resident in Madras, at the time numbering over twenty, inclusive of Inspector-General Mackenzie, C.B., first at my house and then at the Medical College, Madras, before the professors and a large number of medical officers and students, how completely liquor potassæ destroys cobra poison to the eatio. faction of everyone present on both occasions. I here give a paragraph of a letter I received from the secretary to the Inspector-General (the present Surgeon-General with the Government of Madras) which runs as follows :- "3. Should further evidence substantiate your views as to the influence of potash in neutralising the poison within, as you have demonstrated it does without, the body, you will have made a most valuable addition to the common stock of professional knowledge. - (Signed) R. W. CoRNISH, Surgeion, Secretary to Inspector-General I.M.D., Fort St. Gcorge, Feb. 21.st, 1870."

For the "further evidence" called for in this letter I would refer readers to the Madras Mronthly Journal of Medical Science, vol. v., January to June, 1872 , p. 361 , where will be found my remarks on the cure of snake poison I treated with potash successfully. There were three cases; the first was published in THE LANCET, vol. i., 1870, p.540; the second case in the Madras Monthly Journal of Medical Science, vol. i., January to June, 1870 , p. 456 ; and the third case in vol. xiv. of the same journal, July to December, 1871 , p. 102. I would also draw attention to Druitt's "Surgeon's Vade Mecum," eleventh edit,; pp. 139 to '142, where it will be seen I demonstrated by actual experiments the power of liquor potassa to destroy snake poison.

I will now give the notes of the following two cases:-

CASE 1. A policeman was brought to my house at Ercand at 7 P.M. on the evening of the 4th August, 1880, with the report that as he was returning from his beat he was bitten in the foot by a snake, which he produced; and on inspection I found the same to be a young Daboia elegans, or Russell's viper, measuring thirteen inches in length and about the thickness of a man's finger. The patient was in great agony, and was pressing hard with his hand at the groin, where, he said, there was a violent smarting pain. I placed a ligature immediately above the wound, and having no medicines by me, I gave him a stiff glass of brandy, and sent him on at once to the Local Fund Dispensary with a note to the civil apothecary, Mr. T. S. Browne, for further treatment.

'August 4th, 1880.-Madurawoothu (police constable), age twenty-five years, bitten by a snake a little below outer ankle of right foot about three hours previous to admission. Two small punctured wounds to be seen; foot much swollen, and very painful; complains of much giddiness; pulse quick. 